\title{
Fairness in Book Fund Allocation
}

\author{
Jasper G. Schad
}

\begin{abstract}
Efforts to improve book fund allocations have generally focused on developing better formulas, or models, that utilize quantitative measures to determine how the budget will be divided among various subjects. Librarians are attracted to the seemingly rational approach of formulas, but their potential to provide better allocations is limited by the environment in which allocation decisions are made in academic libraries. This environment is characterized by scarce resources, conflicting departmental goals, and a virtually infinite number of factors that affect the need for library resources. Each one of these considerations stimulates deep concern about the fairness and equity of allocations. Research on how recipients view their allocations and the process by which they are made offers insights that can help library administrators and collection developers to manage the allocation process more effectively.
\end{abstract}

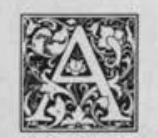

llocating book funds in aca demic libraries should be a rational exercise in making effective and responsible use of the acquisitions budget. All too often, however, extraneous factors work against such an outcome. Schad recognized the political nature of the problem, ${ }^{1}$ and Johnson and Rutstein vividly described how departments work to protect or increase their share of the budget. ${ }^{2}$ These papers brought to light an important dimension of the fund allocation problem but one that is only part of a much larger picture. The intensity with which individual faculty members and whole departments sometimes approach fund allocation represents something more than just trying to capture a larger share of the budget. Both the outcome and the process stir powerful emotions and generate deep feelings about fairness, equity, and justice. ${ }^{3}$ As early as 1953 , Thornton realized that equity is an important consideration in the allocation process. ${ }^{4} \mathrm{McGrath}$, Huntsinger, and Barber also mentioned equity. More recently, Bentley and Farrell saw the need for fairness. ${ }^{6}$ None of these papers, however, explored the concepts of equity and fairness further.

To understand why equity and fairness are so important, one needs only to examine briefly the environment in which allocation decisions are made. It is an environment characterized by scarcity, dissensus, and complexity. Scarcity lowers outcomes and requires people to make sacrifices. A low outcome alone may not create a problem, but an unfairly low outcome does. Normally, people do not worry much about fairness. If there is enough money in the book budget to buy what faculty members want, they are unlikely to be particularly concerned about how the budget is administered. When budgets decline and acquisitions drop, however, the same faculty members are likely to pay a great deal of attention to the issue of fairness and to scrutinize spending and allocating carefully in order to detect any sign of unfairness. Scarcity also increases the probability of unfairness by stimulating competition and self-interest. Dissensus flourishes in organizations that have no strong central authority and no common set of goals. This kind of environment is

Jasper G. Schad is Dean of Libraries, Wichita State University, Wichita, Kansas 67208-1595. 
not unusual in higher education. Colleges and universities are often made of fundamentally autonomous departments whose objectives are varied, conflicting, and changing. It is not even certain that all departments see themselves as engaged in a joint enterprise. The existence of competing values renders attempts to forge an institutional perspective all but impossible. ${ }^{7}$ Even worse, the library can easily become an arena in which battles resulting from institutional discord are fought. Complexity, because it usually increases uncertainty, is the third element that heightens concerns about fairness.

Scarcity, dissensus, and complexity and the concerns about fairness they generate are the principal reasons why allocators like quantifiable formulas. They argue that formulas enhance the limitations of human cognitive powers and assist them in choosing from among many alternatives the one that optimizes the effectiveness of the book budget. In practice, however, librarians are more realistic. They recognize the limits of formulas but still defend them on the grounds that they appear fairer and that faculty are more willing to accept formula-based allocations. ${ }^{8}$ In other words, librarians see formulas as a technique or strategy for defending themselves against challenges to the fairness and equity of allocations. It is important, probably necessary, to convince faculty members and departments that their allocations are fair. The question is whether a formula is the best way to go about that task. It certainly is one possible strategy, but research on what social psychologists call distributive justice ${ }^{9}$ suggests that other ways are more likely to yield better results.

Distributive justice is concerned with allocating resources fairly. There are many theories, all of which share a basic concept-individuals scrutinize their allocations in relation to those of others and the process by which they were made. When they appear reasonable, the allocations seem fair. If not, injustice is perceived. The way individuals react to allocations that they regard as unfair is termed retributive justice. Both the distributive and retributive aspects of allocating book funds are closely related. They can be separated in theory but not in practice. This paper examines the theories and research on distributive and retributive justice in terms of how the book fund allocation process can be improved.

\section{". . . individuals apply their own particular standards of fairness, which is to say that fairness cannot be measured against a single, absolute principle."}

In judging allocations, individuals apply their own particular standards of fairness, which is to say that fairness cannot be measured against a single, absolute principle. It is pretty much what people think it is. The same allocation may seem fair to A but unfair to B. So long as different observers regard each other's inputs, outputs, and needs as being of unequal value, disagreements are inevitable. Perceived unfairness triggers feelings of anger and efforts to secure restitution. One reason for the impact of retributive justice being so powerful is that emotions accelerate toward infinity as the situation worsens, whereas they decelerate only to zero as conditions improve. ${ }^{10}$ Interestingly, evidence suggests that partially correcting an injustice may not help; it may only intensify discontent by recognizing the original injustice. ${ }^{11}$

Victims try to restore psychological or actual equity. Exactly how they go about it, however, varies from individual to individual and according to the circumstances of the situation. ${ }^{12}$ Reactions also depend on how persons weigh the costs and benefits of various approaches. When there is no hope for redressing an injustice, for example, people are not likely to complain forever. ${ }^{13}$

\section{JUSTICE PRINCIPLES}

Outcomes are not the only concern of recipients: how the principles and procedures that shape outcomes are perceived are no less important. If allocators and re- 
cipients are to regard an allocation as fair, they must agree on three things:

1. Principles that guide allocation decisions;

2. Measures that are used in applying those principles;

3. Procedures that are followed.

Even though building consensus on these principles, measures, and procedures is time-consuming, difficult, and likely to be only partially successful, it is still worth the effort, because an allocation that is perceived as fair will be more acceptable.

Three principles-need, contributions, and equality-may serve as the basis for an allocation. ${ }^{14}$ Whether or not the allocation process consciously adopts one of these principles, it will be governed by one or a combination of them.

The principle of need specifies that funds be distributed according to the particular requirements of each discipline. This principle serves institutions that regard the benefits to some departments as more important than the loss to others. Colleges or universities seeking to foster the development and welfare of key departments will find the needs principle attractive. It may also be used to enhance or sustain departments that are developing, expanding, or even experiencing enrollment drops (yet still need as much as a healthy, established department).

The principle of contributions stipulates that funds be apportioned on the basis of the degree to which each department serves the institutional mission. Colleges or universities employing this principle regard departments that contribute most to the mission as making the best use of funds and deserving a larger share of the budget. The contributions principle represents an economic approach, in that what a department receives is outputgoverned. A formulation of this principle states a relationship between each department's productivity and the resources it receives, the assumption being that inputs are related to outputs and that a larger allocation enables it to produce more. Which output measures a college or university prefers will depend on its mission. Research universities may prefer published research, graduate credit-hour pro- duction, and interlibrary loan transactions. Teaching institutions may favor student credit hours and circulation figures.

The principle of equality affords each recipient an equal share, regardless of differences in need or output. Because this principle does not specify exactly what should be equalized, it can be interpreted to mean that departments receive the same total amount ${ }^{15}$ or the same amount for each unit, say, the number of faculty members or majors. The principle of equality is more likely than that of contributions to use input rather than output measures.

Preference for one or more of these distribution principles depends on a variety of factors-institutional and individual. Institutional characteristics favoring one principle or another include the size of the college or university and the level of competition on a particular campus. Impersonal and competitive environments (typically found at large schools) are more likely to favor the contributions principle. Cooperative environments (typically found at smaller institutions) are more inclined toward equality. Where avoiding conflict is a paramount concern, equality will be preferred, because it avoids the need to make judgments about the relative merit of individuals or departments. ${ }^{16}$ Put another way, friends, associates, or individuals who know one another (that is, have relationships with a past and a future) are more likely to divide resources evenly and to benefit the other even at their own expense. ${ }^{17}$ Such relationships strengthen adherence to rules of behavior that resemble a social contract.

Colleges and universities, however, are seldom so monolithic that a single or even a dominant principle can govern the allocation process. Departments and individual faculty members have their own goals, and they will defend principles that place them at an advantage. ${ }^{18}$ In most cases, some balance among the three will have to be maintained. Even then, circumstances and participants frequently change. As departments evolve, so do their ideas about what is needed for their well-being, and their preferences may change. Whatever degree of consensus exists at one 
point in time is likely to break down quickly. ${ }^{19}$

Individual or personal factors are more difficult to assess. Generally, the contributions principle seems fairest to most people ${ }^{20}$ but individual preference for justice norms is highly variable. ${ }^{21}$ Even though individuals want to regard themselves as just, they adopt justice principles primarily in terms of what is in their own best interest. Because they want to deserve what they get, they need approval by others. For that reason, people usually work within certain boundaries. Rather than directly seeking more resources, they select and argue for the distributive principle entitling them to the largest share of funds being allocated and try to convince others to accept it. ${ }^{22}$ Their arguments may be couched in phrases alluding to fairness, but such language is only a thin veneer over an underlying effort to exploit these principles for self-serving ends. ${ }^{23}$

Predictably, weak and powerful departments act differently. Weak departments are likely to argue for equality or need. Their more powerful counterparts do not use power unilaterally to maximize their own outcomes, ${ }^{24}$ rather, they develop arguments (usually for the contributions rule) to buttress their right to receive a larger share of the budget. They do get more resources, although they do not always have their way and receive everything due them by the contributions rule, and frequently agree to an allocation that is intermediate between contributions and equality. ${ }^{25}$

\section{"Even though individuals want to re- gard themselves as just, they adopt justice principles primarily in terms of what is in their own best interest."}

The way participants view themselves and the process also affects their choice of prinicples. Allocators who believe that their ability to control the process results from chance are more likely to favor equality than are those who see themselves as having earned the right to make such a decision. Put another way, people who regard themselves as more deserving favor the contributions principle. ${ }^{26}$

Despite extensive research, however, no comprehensive theory specifies which principle will be best for a particular situation, although it is possible to make some general predictions. Contributions is probably the most disruptive principle because it conflicts with generally accepted academic norms. It implies that different participants do not have the same value and tends to reinforce already strong departments by giving them the resources necessary to maintain or extend their advantage. Contributions-based allocations may also be incompatible with the kind of open decision-making process that is typical in higher education. Preference for the contributions principle declines when decisions are made openly and increases when they are made secretly. ${ }^{27}$

The principle of need has considerable appeal in cases where departments are undergoing change (especially decline) and where fostering personal development is a common goal. Scarcity also seems to favor the needs principle. ${ }^{28}$ The equality principle is even more congenial to higher education because it generally supports relationships of mutual respect. People who work together regularly and share similar values like it. ${ }^{22}$ These findings suggest that small liberal arts colleges will favor equality, whereas larger, more diverse and anonymous universities will be more inclined toward contributions. Yet, in the last analysis, the complex nature of institutions and individuals is so varied and diverse that no single principle is likely to satisfy all participants.

\section{FAIRNESS RULES}

No matter how difficult it is to agree on allocation principles, people are more likely to achieve consensus on principles than on how they should be applied. ${ }^{30}$ The way principles are implemented determines how much each fund gets or, more bluntly, whose ox will be gored. Understandably, procedures will be subject to careful scrutiny. The appearance of fairness in the allocation process can be as im- 
portant as actual fairness. Procedural fairness helps to neutralize concerns about outcomes. There are six procedural rules-consistency, bias-suppression, accuracy, correctability, representativeness, and ethicality. ${ }^{31}$

1. The consistency rule mandates that procedures be uniform over time. All participants must follow the same procedures, which must be applied to all recipients. Once standards are established, frequent, sudden, or marked deviation from them constitutes a violation of fair procedure. Likewise, procedures that have been in place for some time are likely to be taken for granted and raise few questions, regardless of how fair they may or may not be.

2. The bias-suppression rule obliges individuals to exclude personal or departmental self-interest from allocation decisions; one should not serve as judge of one's own case. Failure to separate the adversarial and judicial roles raises questions about fairness.

3. The accuracy rule specifies that allocations should be based on good information and informed opinion. Additionally, safeguards are necessary to ensure that data are not used opportunistically to enhance one's allocation.

4. The correctability rule requires procedures to remedy oversights and errors. The perception of fairness will be enhanced where avenues of appeal permit modifying decisions. Any barrier that prevents dissatisfied individuals from seeking redress reduces the perceived level of fairness.

5. The representativeness rule dictates that allocations must reflect the basic concerns, values, and outlooks of all departments. If a group is involved in developing or reviewing an allocation, it must represent every important segment within the institution.

6. The ethicality rule stipulates that allocation procedures must be fundamentally moral and ethical.

As with other fairness issues, individuals apply these rules selectively. Depending on the circumstances, one rule may be more important than another; or several rules may apply, some of which are contradictory or incompatible. To illustrate, consider the question of whether allocations should be made by individuals or by groups. The argument can be made either way. Consensual decisions seem fairer, because of the representatives rule. People believe that groups protect them because no individual or dominant coalition can impose its preference and disregard the group as a whole. Such is not always the case, however; where there is a high degree of uncertainty, a dominant majority and pressure for quick decisions, differing points of view are often suppressed.

The amount of available information affects the way groups make decisions and how those decisions appear to others. Situations in which there is a great deal of information and certainty are less likely to appear to violate the accuracy rule than are those in which there is a lot of uncertainty. By its very nature, however, the book fund allocation problem is characterized by uncertainty and by having no obviously correct solution. As the level of uncertainty rises, the degree of consensus necessary to obtain group agreement declines. In other words, minority opinions have more influence in complex allocation situations than they do in simple ones. ${ }^{32}$ Thus, in an uncertain environment, committees must be especially careful not to violate or disregard the bias-suppression and accuracy rules.

\section{"... in an uncertain environment, committees must be especially care- ful not to violate or disregard the bias-suppression and accuracy rules."}

Finally, there is one other potential difficulty with committees. Some committees are reluctant to deviate from established procedures. Others, however, especially those that experience frequent changes in membership that bring different perspectives and commitments, often tinker with 
allocations. ${ }^{33}$ In so doing, they ignore the consistency rule.

\section{CONCLUSIONS}

Despite extensive research, scholars have yet to organize their findings into a comprehensive theory that predicts precisely how people will react to specific events and outcomes and, therefore, exactly how to develop an allocation process for a given library. Moreover, existing research is limited in two important ways. Most studies afford participants more information than people receive in real-life situations, and they are conducted in environments where allocators and recipients are strangers. ${ }^{34}$

Knowing more and not having to live with the consequences of a decision can produce experimental results much different from actual behaviors. Given such differences, the value of distributive-justice research is largely speculative and intuitive. The relationship between competition and scarcity illustrates this point. Scarcity encourages competition, and competition leads allocators to favor their own departments. Put another way, departmental loyalties are likely to override broader concerns for fairness when competition becomes intense. ${ }^{35}$ Despite this relationship between scarcity and competition, the most powerful impact is largely indirect. What heightens competition most of all is the perception of a finite sum of money to allocate.

A budget that contains only so many dollars means that department $\mathrm{A}^{\prime}$ s gain is department B's loss. ${ }^{36}$ In other words, it is a zero-sum game, but the process would be better if it were not seen that way. Allocations that award departments percentages of the budget emphasize the gainloss relationship. Allocations that earn departments volumes suggest the deservingness of each department, irrespective of all others. Obviously, the budget is still the same, but it may help to focus attention on what is often the real probleminadequate funding-and not on whether a particular department increases its share of the budget by a percentage point or two.

Finally, this caveat-creating feelings of fairness may not necessarily produce a good allocation. Formulas serve as a case in point. They are attractive mainly because they seem fair. The inherent danger is that they can become a kind of quasifairness that is an end in itself. Exactly the same risk exists with distributive justice. These principles and rules can be used simply to manipulate participants. Despite that possibility, the fact remains that a good allocation stands a poor chance of being accepted if the rules of fairness are violated. Even under the best of circumstances, allocation decisions are often heavily influenced by extraneous factors, such as campus politics and power. Recognizing that these distorting influences can never be completely eliminated, an understanding of the principles and rules of distributive justice and how they can be applied enables librarians to avoid many pitfalls. It afford them insight into the allocation problem and a wider array of options for managing the process in order to achieve a fairer and more acceptable outcome.

\section{REFERENCES AND NOTES}

1. Jasper G. Schad, "Allocating Book Funds: Control or Planning?" College \& Research Libraries 31:155-59 (May 1970).

2. K. Suzanne Johnson and Joel S. Rutstein, "The Politics of Book Fund Allocation: A Case Study," in New Horizons for Academic Libraries, ed. Robert D. Stueart and Richard D. Johnson (New York: K. G. Saur, 1979), p.330-40.

3. Barry Markovsky, "Toward a Multilevel Distributive Justice Theory," American Sociological Review 50:822 (Dec. 1985).

4. Eileen Thornton, "The Small College Library," College \& Research Libraries 14:371 (Oct. 1953).

5. William E. McGrath, Ralph C. Huntsinger, and Gary R. Barber, "An Allocation Formula Derived from a Factor Analysis of Academic Departments," College \& Research Libraries 30:52 (Jan. 1969). 
6. Stella Bentley and David Farrell, "Beyond Retrenchment: The Reallocation of a Library Materials Budget," Journal of Academic Librarianship 10:322 (Jan. 1985).

7. Michael D. Cohen and James G. March, Leadership and Ambiguity: The American College President, 2d ed. (Boston: Harvard Business School, Pr., c. 1986), p.3; Gerald S. Leventhal, "What Should Be Done with Equity Theory?"' in Social Exchange: Advances in Theory and Research, ed. Kenneth J. Gergen, Martin S. Greenberg, and Richard H. Willis (New York: Plenum, c. 1980), p.50; Johnson and Rutstein, p.330-40.

8. Robert E. Burton, "Formula Budgeting: An Example," Special Libraries 66:61 (Feb. 1975); James A. Yunker and Carol G. Covey, "An Optimizing Approach to the Problem of Interdepartmental Allocation of the Library Materials Budget," Library Acquisitions: Practice \& Theory 4:200 (1980).

9. Ronald L. Cohen and Jerald Greenberg, "The Justice Concept in Social Psychology," in Equity and Justice in Social Behavior, ed. Greenberg and Cohen (New York: Academic, 1982), p.141.

10. Markovsky, p.824.

11. Andre deCarufel, "Factors Affecting the Evaluation of Improvement: The Role of Normative Standards and Allocator Resources," Journal of Personality and Social Psychology 37:856 (June 1979).

12. Elaine Hatfield and Susan Sprecher, "Equity Theory and Behavior in Organizations," in Research in the Sociology of Organizations 3, ed. Samuel B. Bachrach and Edward J. Lawler (Greenwich, Conn.: JAI Pr., 1984), p.98-99.

13. George C. Homans, Social Behavior: Its Elementary Forms, rev. ed. (New York: HBJ, 1974), p.253; Hatfield and Sprecher, p. 99.

14. Morton Deutsch, "Equity, Equality, and Need: What Determines Which Value Will Be Used as the Basis of Distributive Justice?" Journal of Social Issues 31, no. 1:137-49 (1975); Leventhal, p. 29.

15. Floyd W. Reeves and John Dale Russell, "The Administration of the Library Budget," Library Quarterly 2:271 (Sept. 1932).

16. Ivan Lansberg, "Hierarchy as a Mediator of Fairness: A Contingency Approach to Distributive Justice in Organizations," Journal of Applied Social Psychology 14:125 (Mar.-Apr. 1984); Deutsch, p.143-47.

17. Brenda Major and Kay Deaux, "Individual Differences in Justice Behavior," in Equity and Justice in Social Behavior, ed. Jerald Greenberg and Ronald L. Cohen (New York: Academic, 1982), p.63-64.

18. Gerald R. Salancik and Jeffery Pfeffer, "The Bases and Use of Power in Organizational Decision Making: The Case of a University," Administrative Science Quarterly 19:462-63 (Dec. 1974).

19. Homans observed that "An inequitable distribution may be no more than one that no longer reflects the actual distribution of power." George C. Homans, "Commentary, " in Advances in Experimental Social Psychology, 9, Equity Theory: Toward a General Theory of Social Interaction, ed. Leonard Berkowitz and Elaine Walster (New York: Academic, 1976), p.244.

20. Gerardo Marin, "The Preference for Equity When Judging the Attractiveness and Fairness of an Allocator: The Role of Familiarity and Culture," Journal of Social Psychology 125:546 (Oct. 1985).

21. R. Scott Tindale and James H. Davis, "Individual and Group Reward Allocation Decisions in Two Situational Contexts: Effects of Relative Need and Performance," Journal of Personality and Social Psychology 48:1150 (May 1985).

22. Elaine Walster, G. William Walster, and Ellen Berscheid, Equity: Theory and Research (Boston: Allyn and Bacon, c. 1978), p.16; Melvin J. Lerner, "Justice Motive in Human Relations," in Justice Motive in Social Behavior, ed. Melvin J. Lerner and Sally C. Lerner (New York: Plenum, c.1981), p.16.

23. Lerner, p.16.

24. Ibid., p.22.

25. S. S. Komorita and Jerome M. Chertkoff, "A Bargaining Theory of Coalition Formation," Psychological Review 80:149-62 (May 1973); S. S. Komorita and K. Leung, "Toward a Synthesis of Power and Justice in Reward Allocation," in Advances in Group Processes, ed. Edward J. Lawler (Greenwich, Conn.: JAI Pr., c.1985), p.175.

26. Elizabeth Hoffman and Matthew L. Spitzer, "Entitlements, Rights, and Fairness: An Experimental Examination of Subjects' Concepts of Distributive Justice," Journal of Legal Studies 14:259-97 (June 1985).

27. Gerald S. Leventhal, "Distribution of Rewards and Resources in Groups and Organizations," in Advances in Experimental Social Psychology, 9, Equity Theory: Toward a General Theory of Social Interaction, ed. Leonard Berkowitz and Elaine Walster (New York: Academic, 1976), p.110-12.

28. Deutsch, p.143; Johnson and Rutstein, p.337.

29. Karen S. Cook and Karen A. Hegtvedt, "Distributive Justice, Equity, and Equality," in Annual Review of Sociology 9, ed. Ralph H. Turner and James F. Shorts, Jr. (Palo Alto, Calif.: Annual Reviews, c.1983), p.223-24. 
30. Homans, p. 232; Johnson and Rutstein, p.330-40.

31. Leventhal, p.39-46.

32. Tindale and Davis, p. 1160 .

33. David C. Genaway, "The Q Formula: The Flexible Formula for Library Acquisitions in Relation to the FTE Driven Formula," Library Acquisitions: Practice \& Theory 10:298 (1986); Johnson and Rutstein, p.330-40.

34. Robert Hogan and Nicholas P. Emler, "Retributive Justice," in Justice Motive in Social Behavior, ed. Melvin J. Lerner and Sally C. Lerner (New York: Plenum, c. 1981), p.129.

35. S. Towson, M. J. Lerner, and A. deCarufel, "Justice Rules or Ingroup Loyalties: The Effects of Competition on Children's Allocation Behavior," paper presented at the annual meeting of the Canadian Psychological Assn., June 1979, summarized in Andre deCarufel, "The Allocation and Acquisition of Resources in Times of Scarcity," in Justice Motive in Social Behavior, ed. Melvin J. Lerner and Sally C. Lerner (New York: Plenum, c.1981), p. 320.

36. deCarufel, "Allocation and Acquisition," p.319-20; Jennifer Boldero and Doreen Rosenthal, "Equity, Compromise, and Competition: Effects of Situational Variables and Type of Allocation Pool," Journal of Social Psychology 123:219 (Aug. 1984). 